\title{
Papers
}

\section{Brief intervention during hospital admission to help patients to give up smoking after myocardial infarction and bypass surgery: randomised controlled trialTopic: 15;144}

\author{
Peter Hajek, Tamara Z Taylor, Peter Mills
}

\begin{abstract}
Objective To evaluate a smoking cessation intervention that can be routinely delivered to smokers admitted with cardiac problems.

Design Randomised controlled trial of usual care compared with intervention delivered on hospital wards by cardiac rehabilitation nurses.

Setting Inpatient wards in 17 hospitals in England. Participants 540 smokers admitted to hospital after myocardial infarction or for cardiac bypass surgery who expressed interest in stopping smoking.

Intervention Brief verbal advice and standard booklet (usual care). Intervention lasting 20-30 minutes including carbon monoxide reading, special booklet, quiz, contact with other people giving up, declaration of commitment to give up, sticker in patient's notes (intervention group).
\end{abstract}

Main outcome measures Continuous abstinence at six weeks and 12 months determined by self report and by biochemical validation at these end points. Feasibility of the intervention and delivery of its components.

Results After six weeks 151 (59\%) and 159 (60\%) patients remained abstinent in the control and intervention group, respectively $(\mathrm{P}=0.84)$. After 12 months the figures were $102(41 \%)$ and $94(37 \%)$ $(\mathrm{P}=0.40)$. Recruitment was slow, and delivery of the intervention was inconsistent, raising concerns about the feasibility of the intervention within routine care. Patients who received the declaration of commitment component were almost twice as likely to remain abstinent than those who did not receive it $(\mathrm{P}<0.01)$. Low dependence on tobacco and high motivation to give up were the main independent predictors of positive outcome. Patients who had had bypass surgery were over twice as likely to return to smoking as patients who had had a myocardial infarction. Conclusions Single session interventions delivered within routine care may have insufficient power to influence highly dependent smokers.

\section{Introduction}

Smoking cessation after myocardial infarction is associated with a significant decrease in mortality. ${ }^{1}$ In cardiac inpatients in general, abstinence from smoking can dramatically reduce the likelihood of readmission to hospital, ${ }^{2}{ }^{3}$ and considerable health benefits follow from even short term abstinence, especially in patients undergoing surgery. ${ }^{4}$ Yet among smokers admitted to hospital after myocardial infarction or to undergo cardiac surgery, up to $70 \%$ start smoking again within a year. ${ }^{6}$

Several studies have examined the efficacy of interventions to help cardiac patients to give up smoking and have reported moderate to good results. ${ }^{711}$ So far, however, only relatively intensive interventions delivered by dedicated staff have been studied. In the context of the UK health service, effective interventions are needed which can be delivered routinely and on a large scale by existing staff. Such interventions should not impose a large additional workload or require substantial new resources.

Virtually all cardiac inpatients abstain from smoking for at least the first few days after a cardiac event or after bypass surgery, and this may provide a unique opportunity for an intervention aimed at preventing a return to smoking after discharge. We evaluated such an intervention implemented by cardiac rehabilitation nurses during their routine work.

\section{Method}

\section{Participants}

The study took place in 17 hospitals in England. Patients admitted after myocardial infarction or for coronary bypass surgery were screened for eligibility. Participants were current smokers or those who had recently stopped smoking. All patients had recovered enough to receive the intervention, had no gross memory impairment, were under 76 years of age, could read English, had not smoked at all since admission to hospital, and were motivated to stop smoking permanently.

\section{Sample size}

With usual care we would expect $30-40 \%$ of participants not to start smoking again for at least 12 months. A sample of 244 participants in each group would give a $90 \%$ probability of detecting a $15 \%$ increase in abstinence rates and $80 \%$ probability of detecting a $13 \%$ difference ( $\alpha=0.05$, two tailed test). We estimated that up to $10 \%$ of the sample would be lost

\author{
Department of \\ Human Science \\ and Medical Ethics, \\ Bart's and The \\ London, Queen \\ Mary's School of \\ Medicine and \\ Dentistry, London \\ E1 2AD \\ Peter Hajek \\ professor of clinical \\ psychology \\ Tamara Z Taylor \\ research psychologist \\ London Chest \\ Hospital, London \\ E2 9JA \\ Peter Mills \\ consultant \\ cardiologist \\ Correspondence to: \\ P Hajek \\ p.hajek@qmul.ac.uk
}

BMJ 2002;324:1-6 
to follow up because of death or moving to an unknown address, and therefore we aimed to recruit 540 participants.

\section{Procedures}

The cardiac rehabilitation nurses recruited eligible patients on wards. Participants signed the consent form, filled in the study questionnaire, and were randomised to the intervention or control group on a 1:1 ratio by nurses opening a serially numbered, opaque, sealed envelope designating the patient's allocation. The randomisation was in batches of 20 with envelopes provided to each nurse.

All participants in the control group received verbal advice to remain abstinent and a British Heart Foundation booklet Smoking and your Heart. Participants in the intervention group also received a carbon monoxide reading to show the health benefits of quitting; a booklet on smoking and cardiac recovery that challenged the belief that smoking alleviates stress and provided advice on avoiding relapse; a written quiz on the contents of the booklet, which was subsequently discussed with the nurse, to improve retention and understanding of the information; and an offer to be put in contact with another cardiac patient who had also recently stopped smoking to provide mutual support (a "buddy"). There is evidence that such support can be effective. ${ }^{12}$ Participants in the intervention group also had a declaration of commitment not to smoke that they had signed as a motivational reminder. A sticker was placed on their notes as a reminder to the staff to reinforce the intervention at future contacts.

The cardiac nurses recorded which elements of the intervention they implemented and the duration of the intervention. Before the study started, six nurses in five hospitals piloted the intervention and necessary changes were made. The pilot work suggested that the intervention took about 20 minutes of nurses' time.

\section{Outcome measures}

We defined participants as being continuously abstinent if they reported that they had smoked no more than five cigarettes (or "roll-ups," cigars, or pipes) since recruitment and had not smoked at all in the past week. They also had to have an expired carbon monoxide reading $<10$ ppm and, at 12 months, a salivary cotinine concentration $<20 \mathrm{ng} / \mathrm{ml}$. We defined point prevalence abstinence as a self report of not having smoked at all for the past week and an expired carbon monoxide reading $<10$ ppm or, for the 12 month outcome, a salivary cotinine concentration $<20 \mathrm{ng} / \mathrm{ml}$.

Nurses recorded their own compliance with individual study procedures by ticking the intervention elements listed on the form. They also noted the dura-

Table 2 Number (percentage) of participants not smoking (abstinence rate) at each follow up

\begin{tabular}{lcccc}
\begin{tabular}{l} 
Measure of abstinence \\
\hline Six weeks
\end{tabular} & Control group & $\begin{array}{c}\text { Intervention } \\
\text { group }\end{array}$ & $\begin{array}{c}\text { Mean difference in rates } \\
\mathbf{( 9 5 \%} \mathbf{~ C l )}\end{array}$ & P value \\
\hline Continuous abstinence & $152(59)$ & $159(60)$ & $0.9(-7.5$ to 9.3) & 0.84 \\
\hline Point prevalent abstinence & $154(60)$ & $160(60)$ & $0.5(-7.9$ to 8.8) & 0.91 \\
\hline Twelve months $\dagger$ & & & & \\
\hline Continuous abstinence & $102(41)$ & $94(37)$ & $-3.6(-12.1$ to 4.9) & 0.40 \\
\hline Point prevalent abstinence & $108(40)$ & $99(39)$ & $-4.1(-12.6$ to 4.5) & 0.35 \\
\hline
\end{tabular}

*Control $n=259$, intervention $n=267$.

tControl $n=251$, intervention $n=254$.
Table 1 Baseline characteristics of participants admitted to hospital after myocardial infarction or for bypass surgery

\begin{tabular}{lcc} 
& $\begin{array}{c}\text { Control } \\
(\mathbf{n}=\mathbf{2 6 6 )}\end{array}$ & $\begin{array}{c}\text { Intervention } \\
(\mathbf{n}=\mathbf{2 7 4 )}\end{array}$ \\
\hline Men & 207 & 210 \\
\hline Mean (SD) age (years) & $56(10)$ & $56(10)$ \\
\hline Married/living with partner & 184 & 194 \\
\hline No educational qualifications & 171 & 177 \\
\hline In paid employment & 116 & 110 \\
\hline Retired & 86 & 96 \\
\hline Myocardial infarction & 253 & 252 \\
\hline Bypass surgery & 13 & 22 \\
\hline Mean (SD) time since admission/operation (days) & $4.6(3.4)$ & $4.9(4.6)$ \\
\hline Stopped smoking before hospital admission & 68 & 75 \\
\hline Mean (SD) No of cigarettes/day & $21.1(11.4)$ & $22.6(13.0)$ \\
\hline Mean (SD) minutes to first smoke in morning & $45.7(107.5)$ & $42.1(96.9)$ \\
\hline Thought smoking made condition worse & 231 & 233
\end{tabular}

tion of the intervention. Patients recorded their recall of the intervention by ticking items on a self completed questionnaire at the six week follow up.

\section{Follow up}

Data at the six week follow up were collected by nurses at the time of the routine hospital visit after discharge, or patients were visited at home. Carbon monoxide concentration was recorded in all participants who claimed to have stopped smoking and also in those in the intervention group who had not stopped smoking. This was to motivate abstinence, if nurses thought it was appropriate and worth while.

At 12 months participants were telephoned. If they said they had stopped smoking a home visit was arranged to collect a carbon monoxide reading and a saliva sample for cotinine analysis. If a home visit was not possible, a saliva collection kit was sent to the participant instead.

Data analysis

We used logistic regression analyses to assess the relation between baseline measures and outcomes. We assessed the effect of the intervention with $\chi^{2}$ tests and $95 \%$ confidence intervals and multiple logistic regressions to control for possible confounding variables. All $\mathrm{P}$ values are two tailed.

\section{Results}

Recruitment to the study was slower than expected so the recruitment period had to be extended to 30 months. There were no significant differences between the intervention and control groups in any of the baseline characteristics (table 1). Most participants were heavy smokers who smoked their first cigarette each morning within 30 minutes of waking up.

\section{Follow up and sample attrition}

By six weeks 65 patients (12\%) were lost to follow up, 14 of whom had died. By 12 months 60 participants were lost to follow up, 26 of whom who had died (12 in addition to 14 who died by six weeks), and nine had moved away to unknown addresses. There were no significant differences in numbers lost to follow up (26 and 34 , respectively) or numbers who died or moved away (15 and 20, respectively) between the two groups. Participants who had died or moved to unknown addresses were removed from the sample; those not 
available for follow up for other reasons were counted as smokers. Our final sample for analysis was 526 at six weeks and 505 at 12 months.

We measured cotinine concentration in saliva samples of 217 out of the 229 participants who reported that they had stopped smoking at 12 months. In five cases analysis was not possible or appropriate (for example, when the person was using nicotine replacement therapy) so we used a carbon monoxide reading to validate abstinence. In seven cases, neither measure of validation was available, and we classified participants as smokers.

\section{Smoking cessation rates}

Table 2 shows validated abstinence rates at six weeks and 12 months. There were no significant differences between the two groups.

\section{Adherence to the intervention procedures}

Table 3 shows that almost every patient in the intervention group was given a carbon monoxide reading and the study booklet. Less than 70\% (178) signed a commitment card or were told about the opportunity to be paired with a "buddy." In only 7\% (33) did nurses note that the "buddy" offer was accepted, and in only 4\% (12) was the actual pairing with another patient recorded as having been organised. There was a significant difference in the mean number of elements implemented by each study site $\left(F_{16.257}=4.2, \mathrm{P}<0.0005\right)$.

Table 3 Number (percentage) of participants in intervention group who received each element of intervention, as logged by cardiac rehabilitation nurses

\begin{tabular}{lc} 
Element & No (\%) of patients \\
\hline Measured expired carbon monoxide & $271(99)$ \\
\hline Given booklet to read & $270(99)$ \\
\hline Discussed answers to quiz & $242(88)$ \\
\hline Signed commitment card & $191(70)$ \\
\hline Offered to put in touch with "buddy" & $178(65)$ \\
\hline Buddy contact arranged & $12(4)$ \\
\hline Put sticker on records & $238(87)$ \\
\hline Arranged follow up appointment & $197(72)$ \\
\hline
\end{tabular}

We used a set of logistic regressions (one for each measure of abstinence) to examine the relation between abstinence and the number of elements of the intervention implemented. The regressions were nonsignificant for abstinence at six weeks, but significant for abstinence at 12 months (odds ratio 1.4, 1.1 to 1.9, $\mathrm{P}=0.003$, for continuous abstinence and $1.3,1.0$ to 1.6, $\mathrm{P}=0.003$, for point prevalent abstinence). The only individual item that predicted continuous abstinence at 12 months was signing the commitment card; $43 \%$ of those who signed the card remained abstinent compared with $22 \%$ of those who did not (1.6, $\mathrm{P}=0.002$ ).

The intervention took an average of 34 minutes to implement (range 4-85 minutes), including obtaining informed consent and filling in the study questionnaire. A logistic regression showed no linear relation between the duration of the intervention and abstinence rates.

Table 4 shows the proportion of participants from each group who reported remembering each intervention element. Though the people in the control group did not receive the intervention, a substantial
Table 4 Number (percentage) of patients recalling each intervention element at six week follow up

\begin{tabular}{lcrr} 
& $\begin{array}{c}\text { Intervention } \\
\text { group* }\end{array}$ & Control group† & P value $\left(\chi^{2}\right)$ \\
\hline Expect higher recall in intervention group & & & \\
\hline Discussed smoking more than once & $168(72)$ & $156(69)$ & 0.400 \\
\hline Measured expired carbon monoxide & $215(91)$ & $32(15)$ & $<0.001$ \\
\hline Explained why stopping smoking may be difficult & $207(90)$ & $151(68)$ & $<0.001$ \\
\hline Checked understanding of information booklet & $210(90)$ & $115(53)$ & $<0.001$ \\
\hline Offered to find buddy & $127(55)$ & $23(10)$ & $<0.001$ \\
\hline $\begin{array}{l}\text { Suggested signing declaration of commitment to stay } \\
\text { off smoking }\end{array}$ & $214(93)$ & $63(29)$ & $<0.001$ \\
\hline Expect equal recall in both groups & & & \\
\hline Discussed smoking & $232(100)$ & $223(99)$ & 0.080 \\
\hline Explained that smoking is dangerous & $222(95)$ & $179(85)$ & $<0.001$ \\
\hline Gave booklet to read & $73(35)$ & $31(15)$ & $<0.001$ \\
\hline Suggested other treatments or gave other advice & & \\
\hline Patient's attitude towards advice & $13(6)$ & $9(4)$ & 0.001 \\
\hline Found advice helpful & $115(50)$ & $95(43)$ & 0.100 \\
\hline Resented advice &
\end{tabular}

${ }^{*} \mathrm{No}=210-236$, varies because of missing data.

$\dagger \mathrm{N}_{0}=201-213$, varies because of missing data.

proportion of them "recalled" various procedures. Almost half of all participants "recalled" a non-existent control item (advice to drink water). The recall of advice did not differ in smokers and abstainers. Encouragingly, most members of both groups found the advice they were given to be helpful, with the intervention group finding the advice significantly more helpful than the control group. Only a few patients resented the advice.

\section{Predictors of outcome}

Of the baseline variables listed in table 1, older age, having a partner, having educational qualifications, smoking fewer cigarettes per day, waiting longer before smoking the first cigarette of the day, and wanting to remain abstinent were all positive predictors of at least one measure of abstinence. Patients who had had a myocardial infarction were much more likely to be abstinent at 12 months compared with patients who had undergone bypass surgery (191/280 $v 5 / 29)$.

We analysed all these variables together with group allocation and study with a multivariate logistic regression equation. Table 5 shows the five variables that remained in the equation as predictors of outcome.

Table 5 Predictors (odds ratios from logistic regression analysis) of continuous abstinence at 12 months adjusted for other significant variables in table and group allocation

\begin{tabular}{lcc} 
& $\begin{array}{c}\text { Univariate } \\
\text { predictor }\end{array}$ & $\begin{array}{c}\text { Adjusted for other } \\
\text { variables }\end{array}$ \\
\hline Age & $1.02^{*}$ & $1.03^{*}$ \\
\hline Reason for admission: & \\
\hline Myocardial infarction $v$ bypass surgery & $1.99^{*}$ & $2.48 \dagger$ \\
\hline Marital status: & $1.37 \dagger$ \\
\hline Partner $v$ no partner & $1.35^{\star}$ \\
\hline Time to first cigarette in morning: & \\
\hline$>30$ mins $v<30$ mins & $1.44 \ddagger$ \\
\hline Plans regarding smoking: & \\
\hline Determined not to $v$ would rather not & $1.56 \ddagger$ \\
\hline Group: & \\
\hline Intervention $v$ control & 0.93 & \\
\hline
\end{tabular}




\section{Discussion}

This study showed that a single intervention to prevent return to smoking in cardiac inpatients after discharge from hospital was not effective. We believe that this is the first study to investigate a procedure that could be delivered routinely by existing staff. Our study also differed from previous trials with cardiac patients in that all self reports of abstinence were validated, and the primary outcome measure was continuous abstinence since the intervention. The study was also the largest so far.

Several issues may be relevant in the interpretation of our findings. The usual care may have provided a standard that was too high. Also, there may have been some contamination between the groups. However, in view of the fact that we recruited only those patients who were keen to remain abstinent, the abstinence rates suggest that neither intervention had much impact rather than that substantial impact was made by both.

The intervention was not always fully implemented; elements that were designed to encourage ongoing support were often left out. Implementation was related to outcome; in particular, signing the commitment card was strongly associated with successful abstinence. This is only an observational finding, and, although the commitment card was included in the belief that formalising the attempt to quit in this manner would be beneficial, the possibility remains that the intervention was offered preferentially to keen patients or that only those who were confident that they would be able to give up signed the form. More intensive training and rehearsal of the behavioural procedures may improve their delivery. However, time demands represented a serious barrier, and the existing requirements of the training and the intervention proved to be on the borderline of feasibility. The more complex behavioural approaches may not be suitable for routine implementation by non-specialist staff.

The intervention was given at a time when patients may have been too distraught or anxious to absorb the details of the intervention. However, at follow up patients remembered and appreciated the advice. Also, there are no other suitable times for input on prevention of relapse before patients are discharged. Later on, cardiac rehabilitation classes offer intervention opportunities, but many patients start to smoke again by then, and not all patients attend the classes.

The most likely explanation of the negative finding is that a single session intervention is not enough to reach this highly dependent group of smokers. This has been observed with other such groups. ${ }^{13-15}$ The literature suggests a dose-response with regard to the intensity of the intervention, with the most successful results in cardiac patients occurring with an intervention consisting of eight contacts taking altogether three and a half hours.

It may not be feasible for more intensive interventions to become part of routine care by staff whose primary responsibilities lie elsewhere. We were impressed with the overall competence and spirit of cardiac rehabilitation nurses, but even these highly motivated workers were unable to recruit suitable patients and to deliver the more involved elements of the intervention
What is already known on this topic

Stopping smoking after a serious cardiac event is associated with a significant decrease in mortality

Up to $70 \%$ of smokers who survive cardiac surgery smoke again within a year

Intensive interventions delivered by dedicated staff can help cardiac patients not to start to smoke again

\section{What this study adds}

An intervention delivered by cardiac rehabilitation nurses within routine care during patients' hospital stay failed to increase the number who managed to stop smoking in the long term

For busy staff with competing priorities, the 30 minute intervention was also on the borderline of practicability

Patients admitted after a myocardial infarction were over twice as likely to give up than those admitted for a bypass operation

consistently because of pressure on time and competing priorities.

Overall, the results are challenging and of direct practical relevance. Advice by doctors and nurses reaches primarily light "non-dependent" smokers. ${ }^{16}$ Patients who suffer serious health consequences of their smoking, are keen to stop, and yet carry on smoking are typically highly dependent, and single interventions do not seem to have sufficient power to help them. In these groups, interventions comprising several session with specialists have been shown to be effective. ${ }^{17}$ The new specialist smoking cessation services, which are funded by the government and are now established in all health authorities to provide intensive behavioural and pharmacological treatments over several, should collaborate with staff on wards and include hospital patients as one of their priority target groups.

We thank the cardiac rehabilitation nurses who took part in this study and their managers for the high quality of their input. The following hospitals took part: Barnet General, Basildon, Crawley, Derriford in Plymouth, Epsom General, Greenwich District, Homerton, Joyce Green in Dartford, King's College, The London Chest, Newham General, Royal Brompton and Harefield, The Royal London, Royal Sussex County in Brighton, St Bartholomew's, St George's in London, and Whittington. We are grateful to Enid Hennessy for her advice on statistics. Tracy Thorns helped to set up and start the study, and Rachel Evans implemented a major part of it; their help was essential for this project.

Contributors: PH contributed to conception and design, analysis and interpretation of data, and writing the paper and is guarantor. TT contributed to analysis and interpretation of data and writing the paper. PM contributed to conception and design and writing the paper.

Funding: NHS research and development programme on cardiovascular disease and stroke.

Competing interests: None declared.

1 Wilson K, Gibson N, Willan A, Cook D. Effect of smoking cessation on mortality after myocardial infarction: meta-analysis of cohort studies Arch Intern Med 2000;160:939-44.

2 Department of Health and Human Services (US). The health benefits of smoking cessation: a report of the surgeon general. Rockville, MD: Public Health Service, Office on Smoking and Health, 1990. 
3 Cavender JB, Rogers WJ, Fisher LD, Gersh BJ, Coggin CJ, Myers WO. Effects of smoking on survival and morbidity in patients randomized to medical or surgical therapy in the coronary artery surgery study: 10-year follow-up. J Am Coll Cardiol 1992;20:287-94.

4 Jones RM, Rosen M, Seymour L. Smoking and anaesthesia. Anaesthesia 1987;42:1-2.

5 Dobson AJ, Alexander HM, Heller RF, Lloyd DM. How soon after quitting smoking does risk of heart attack decline? J Clin Epidemiol 1991;44:1247-53.

6 Rigotti NA, Singer DE, Mulley AG Jr, Thibault GE. Smoking cessation following admission to a coronary care unit. J Gen Intern Med 1991;6:30511.

7 Rigotti NA, McKool KM, Shiffman S. Predictors of smoking cessation after coronary artery bypass graft surgery. Results of a randomized trial after coronary artery bypass graft surgery. Results of a

8 Ockene J, Kristeller JL, Goldberg R, Ockene I, Merriam P, Barrett S, et al Smoking cessation and severity of disease: the coronary artery smoking intervention study. Health Psychol 1992;11:119-26.

9 Taylor CB, Houston-Miller N, Killen JD, DeBusk RF. Smoking cessation after acute myocardial infarction: effects of a nurse-managed intervention. Ann Intern Med 1990;113:118-23.

10 DeBusk RF, Miller NH, Superko HR, Dennis CA, Thomas RJ, Lew HT, et al. A case-management system for coronary risk factor modification after acute myocardial infarction. Ann Intern Med 1994;120:721-9.
11 Dornelas EA, Sampson RA, Gray JF, Waters D, Thompson PD. A randomized controlled trial of smoking cessation counselling after myocardial infarction. Prev Med 2000;30:261-8.

12 West R, Edwards M, Hajek P. A randomized controlled trial of a "buddy" system to improve success at giving up smoking general practice. Addiction 1998;93:1007-11.

13 Klesges RC, Haddock CK, Lando H, Talcott GW. Efficacy of forced smoking cessation and an adjunctive behavioral treatment on long-term smoking rates. J Consult Clin Psychol 1999;67:952-8.

14 Stevens VJ, Glasgow RE, Hollis JF, Mount K. Implementation and effectiveness of a brief smoking-cessation intervention for hospital patients. Med Care 2000;38:451-9.

15 Hajek P, West R, Lee A, Foulds J, Owen L, Eiser R, et al. Randomised controlled trial of a midwife-delivered brief smoking cessation intervention in pregnancy. Addiction 2001;96:485-94.

16 Royal College of Physicians. Nicotine addiction in Britain. London: Royal College of Physicians, 2000.

17 West R, McNeill A, Raw M. Smoking cessation guidelines for health professionals: an update. Thorax 2000;55:987-99.

(Accepted 7 September 2001) 